\title{
Reading Customers Needs and Expectations with Analytics
}

\author{
Vasilis Aggelis \\ Pireus Bank \\ aggelisv@piraeusbank.gr
}

\begin{abstract}
Customers are the greatest asset for every bank. Do we know them in whole? Are we ready to fulfill their needs and expectations? Use of analytics is one of the keys in order to make better our relation with customers. In advance, analytics can bring gains both for customers and banks. Customer segmentation, targeted cross- and up-sell campaigns, data mining utilization are tools that drive in great results and contribute to customer centric turn.
\end{abstract}

